\title{
EDITORIAL
}

Early phase studies

\section{Can a disease be conquered by extensive publications, reading guidelines and interminable meetings?}

\author{
Robert Peter Gale ${ }^{1}$
}

Received: 15 May 2020 / Revised: 24 May 2020 / Accepted: 26 May 2020 / Published online: 11 June 2020

(c) Springer Nature Limited 2020

Early in the War Against Cancer when huge amounts of federal funds were funneled into cancer research some cynics commented: more people were living from than dying from cancer. Fortunately, we have made substantial progress against cancer even if victory is not yet ours. Another situation which comes to mind is hairy cell leukaemia (HCL). In the 1970s many people with HCL were referred to Profs. David Golde at UCLA or Harvey Golumb at the Univ. Chicago. We were in a vigorous academic competition but the only intervention we had then was splenectomy, surprisingly effective in some people but was not usually a cure. What to do? Golde suggested: If we can't cure hairy cell leukaemia perhaps we can publish it to death.

To understand whether the SARS-CoV-2 pandemic can be conquered by extensive publications, reading guidelines and interminable meetings I searched PubMed for citations with the search term and Boolean operators SARS-CoV-2 AND/ OR COVID-19. I had 12,475 hits over the 1st 3 months of the pandemic. In a similar search of PubMed for acute myeloid leukaemia, I had 12,475 hits over 54 years equating to 231 per year of about 20 in a 3-month interval. These data suggest a publication rate for SARS-CoV-2 and/or COVID-19 about 650-fold higher. (Disclosure: I published 7 typescripts on this topic [1-7]. He that is without sin among you, let him first cast a stone at her. John 8:7) And this is only for journals in PubMed. Who knows how many were published in other journals, rejected published as correspondence, etc.?

The most obvious explanation of this burst of publications is the global interest in SARS-CoV-2. However, other forces may be at work. It is well known and contrary to expectations, submissions to scientific and medical journals

\footnotetext{
Robert Peter Gale

robertpetergale@alumni.ucla.edu

Imperial College London, London, UK
}

increase dramatically over the Christmas New Year holiday break and on weekends. Fifteen percent of researchers submitting typescripts do so over these intervals. Now consider most scientists' laboratories are closed and most clinicians are not directly involved in treating persons with COVID-19 and in locked down at home facing the choice of playing with the kids or sequestering in a home office finally finishing and submitting that long delayed typescript. What would you do? My recommendation, especially to young investigators, those most likely to have young kids and those seeking promotion: Get on this quickly; a once in a lifetime opportunity. Publish or perish (from COVID-19).

What of guidelines? Can they cure COVID-19? A PubMed search I did on 14 May, 2020 identified 567 guidelines. To evaluate their value I randomly selected 20 and studied the quality of evidence on which they were based using the US Preventative Diseases Task Force (USPDTF) guidelines of Grade strength of a recommendation and Certainty of the conclusion (https://uspreventiveservicestaskforce.org/uspstf/gra de-definitions) (None of these COVID-19 or SARS-CoV-2 guidelines is yet formally reviewed by the USPDTF.) For those unfamiliar with these metrics, Grade ranges from A (There is high certainty the net benefit is substantial) to D (Discourage use) with an I category (Current evidence is insufficient to assess the balance of benefits and harms). Levels of Certainty range from high (The available evidence includes consistent results from well-designed, well-conducted studies) to low (The available evidence is insufficient to assess effects on health outcomes.) Readers will not be surprised the 20 guidelines I reviewed had Grades of $\mathrm{C}$ and I and all had a low level of evidence. Many of the guidelines were common sense and may be useful. However, lack of evidence supporting the recommendations in these guidelines should give pause.

I also reviewed guidelines from two transplant-related groups, European Bone Marrow Transplant Group (EBMT; https://www.ebmt.org/ebmt/news/coronavirusdisease-covid-19-ebmt-recommendations-update-march23-2020) and American Society for Transplantation and Cellular Therapy (ASTCT; https://higherlogicdownload. 
s3.amazonaws.com/ASBMT/a1e2ac9a-36d2-4e23-945c45118b667268/UploadedImages/COVID-19_Interim _ Patient_Guidelines_4_20_20.pdf) and one from the UK National Institute for Health and Care Excellence (NICE; https://www.nice.org.uk/guidance/ng164) for persons receiving hematopoietic cell transplants or cell therapies such as chimeric antigen receptor-T cells. I gave these guidelines a Grades C or I and a low Certainty score. Again, these recommendations were sensible and may be useful. However, I often see these guidelines cited and read with people saying: We followed guidelines from the XXX. Really?

To test whether my conclusions regarding the impact and value of these guidelines are valid (subtly but importantly different than testing validity of my conclusions), I divided 70 C57Black/6J mice into equal cohorts, printed a copy each of the 20 guidelines, collated and then shredded them. I used these or conventional sawdust as cage liners for the mice. After a week I combined the mice in each and placed them into two large garbage bins containing a wedge of parmesan cheese (from Costco) on which I wrote COVID19 destroy! There was no statistically significant difference in the time it took the mice to consume the cheese. Validation!

What of interminable meetings? Can these cure COVID19? This question was reviewed in a recent (pseudo) NEJM typescript (http://commentary-gonzalo86.blogspot.com/2020/ 04/interminable-meetings-found-ineffective.html). Not surprisingly, the answer seems no. And with Zoom interminable meetings keep people off the streetan added bonus of audioonly conferences is the ability to check e-mails and finish typescripts on SARS-CoV-2 and COVID-19 to submit (see above)

What if the SARS-CoV-2 pandemic subsides during the interval of extensive publications, reading guidelines and interminable meetings? Can we say these actions were the cure? Problems again. First, these actions are confounded although some would argue reading endless guidelines and attending interminable meeting must decrease submitting typescripts. Second, as in all epidemiological studies we should not confuse association with cause and effect. The pandemic mat resolve because or despite extensive publications, reading guidelines and interminable meetings. One correlate of all this academic activity is crime rates have dropped. Is it because scientists are the criminals or because everyone is staying at home? This again illustrates the mistake of confusing associations with cause and effect as we pointed out in a recent typescript: Why there is a strong correlation between people drowning after falling out of a fishing boat and marriage rate in Kentucky [8].

Not everything is so murky. We need effective public health measures, drugs and vaccines to conquer SARSCoV-2 and COVID-19. Extensive publications, more guidelines and interminable meetings will not get us there. So back to Golde's suggestion: Can we publish a disease to death? It seems not. However, despite these distractions the global scientific and medical communities have made a spectacular effort to confound the SARS-CoV-2 pandemic and the world is grateful. But the battle is not over. Whether this plethora of publications, guidelines and interminable meeting have helped in some yet undetectable way is unknown and likely unknowable. Perhaps when the dust settles and we have time for a rigorous evaluation of what is effective and ineffective, we can be better prepared for the next coronavirus pandemic.

\section{References}

1. Gale RP. Perspective: SARS-CoV-2, COVID-19 and haematologists. Acta Haematol. 2020. https://doi.org/10.1159/000508021.

2. Li H, Chen C, Hu F, Wang J, Zhao Q, Gale RP, et al. Impact of corticosteroid therapy on outcomes of persons with SARS-CoV-2, SARS-CoV, or MERS-CoV infection: a systematic review and meta-analysis. Leukemia. 2020. https://doi.org/10.1038/s41375-0200848-3.

3. He W, Chen L, Chen L, Yuan G, Fang Y, Chen W, et al. COVID19 in persons with haematological cancers. Leukemia. 2020. https://doi.org/10.1038/s41375-020-0836-7.

4. Gale RP. Prespective: cell therapy, SARS-CoV-2, COVID-19, and James Lind. Adv Cell Gene Ther. 2020. In press.

5. Li Q, Cao Y, Chen L, Wu D, Yu J, Wang H, et al. Hematological features of persons with COVID-19. Leukemia. 2020. In press.

6. Li W, Wang D, Guo J, Yuan G, Yang Z, Gale RP. COVID-19 in persons with chronic myeloid leukaemia. Leukemia. 2020:1-6. https://doi.org/10.1038/s41375-020-0853-6.

7. Chen L, Yu J, He W, Chen L, Dong L, Chen W. Risk factors for death in 1,859 subjects with COVID-19. Leukemia. 2020. In press.

8. Gale RP, Zhang MJ. Statistical analyses of clinical trials in haematopoietic cell transplantation or why there is a strong correlation between people drowning after falling out of a fishing boat and marriage rate in Kentucky. Bone Marrow Transplant. 2020;55:1-3. 